\title{
Impact of HLA-DPB1 Matching in Unrelated Allogeneic Stem Cell Transplantation: Results of Two Centers From Turkey
}

\author{
Bulent KANTARCIOGLU ${ }^{1}$, Huseyin S. BEKOZ ${ }^{1}$, Ipek Y. HINDILERDEN² ${ }^{2}$ Demet KIVANC $^{1}$, \\ Yeliz D. OGRET ${ }^{3}$, Sevgi K. BESISIK ${ }^{2}$, Fatma S. OGUZ ${ }^{3}$, Deniz SARGIN ${ }^{1}$ \\ ${ }^{1}$ Istanbul Medipol University, Faculty of Medicine, Department of Internal Medicine, Division of Hematology \\ ${ }^{2}$ Istanbul University, Istanbul Faculty of Medicine, Department of Internal Medicine, Division of Hematology \\ ${ }^{3}$ Istanbul University, Istanbul Faculty of Medicine, Department of Medical Biology, Istanbul, TURKEY
}

\begin{abstract}
In this study, we retrospectively examined 34 donor/recipient transplant pairs fully tested for the alleles HLA-A, B, C, DRB1, DQB1 and DPB1 in two different centers in Istanbul, Turkey. HLA-DPB1 disparity in at least one antigen level was $79.6 \%$ and only $20.6 \%$ of transplant pairs were fully identical for HLA-DPB1, in our study group. Neutrophil and thrombocyte engraftment successfully occurred in the entire study group. When the occurrence of severe (Grade III-IV) aGVHD was taken into account, we have observed that, non-permissive HLA-DPB1 mismatches were a significant factor for development of severe aGVHD $(p=0.019)$. There was a trend of increasing significance for the gut $(p=0.006)$ and liver ( $p$ : 0.054) aGVHD but not for skin aGVHD in non-permissive HLA-DPB1 mismatched transplantations. In multivariate analysis, non-permissive HLA-DPB1 mismatches remained as an independent factor for severe aGVHD. Our results did not show a significant impact of HLA-DPB1 mismatches on relapse. In survival analysis, both HLADPB1 disparities and non-permissive mismatches showed a decreasing trend of event free and overall survival times. Considering these results during donor selection may improve transplant outcomes in the setting of unrelated ASCT.
\end{abstract}

Keywords: Allogeneic stem cell transplantation, GVHD, Human leukocyte antigen, HLA-DPB1

ÖZET

Akrabadişi Allojeneik Kök Hücre Naklinde Hla-Dpb1 Tayininin Önemi: Türkiye'den İki Merkezin Sonuçları

Çalışmamızda, İstanbul, Türkiye'de bulunan 2 farklı merkezde takip ettiğimiz ve HLA-A, B, C, DRB1, DQB1 ve DPB1 için tam olarak test edilmiş, 34 donör/alıcı çiftinin akraba-dışı allojeneik kök hücre nakli verileri geriye dönük olarak incelendi. En az bir antijen seviyesinde HLA-DPB1 uyumsuzluk oranı \%79.6 olarak saptandı. Sadece \%20.6 transplant çiftinde HLA-DPB1 tam uyumlu olduğu görüldü. Nötrofil ve trombosit engraftmanı tüm hasta grubuda başarılı bir şekilde meydana geldi. Şiddetli (Derece III-IV) aGVHH dikkate alındığında, nonpermisif HLA-DPB1 uyumsuzluklarının önemli bir faktör olduğu saptandı $(p=0.019)$. Nonpermisif HLA-DPB1 uyumsuzluğu bulunan nakillerde barsak ( $p=0.006$ ) ve karaciğer ( $p$ : 0.054) aGVHH'nda artış saptanırken, cilt aGVHH'da bu bulguya rastlanmadı. Çok değişkenli analizde, permisif olmayan HLA-DPB1 uyumsuzlukları şiddetli aGVHH için bağımsız bir faktör olduğu görüldü. HLA-DPB1 uyumsuzluklarııı relaps üzerine anlamlı bir etkisinin olmadığı görüldü. Sağkalım analizinde, hem HLA-DPB1 uyumsuzluklarının, hem de nonpermisif uyumsuzlukların olaysız ve genel sağkalım zamanlarında azalma eğilimine neden olduğu görüldü. Donör seçimi sırasında bu sonuçların gözönüne alınması akraba-dışı allojeneik kök hücre nakli sonuçlarını iyileştirebilir.

Anahtar Kelimeler: Allojeneik kök hücre nakli, GVHH, İnsan lökosit antijeni, HLA-DPB1 


\section{INTRODUCTION}

Allogeneic stem cell transplantation (ASCT) is a treatment of choice for many malignant and nonmalignant hematological diseases. In ASCT, human leukocyte antigen (HLA) compatibility between donors and recipients is one of the most important determinants, affecting post-transplant survival and relapse. Recently conducted studies have shown that the disparities in HLA-DPB1 may have a negative impact on the development of acute graft versus host disease and overall survival after ASCT. ${ }^{1}$ In addition, the nature of the disparity, whether it is a permissive and non-permissive mismatch of the HLA-DPB1, can have a further impact on the outcome. Recent research developed a functional 'epitope-based' algorithm analyzing HLA-DPB1 mismatches, based on T-cell alloreactivity patterns targeted to HLA-DPB1 antigens. This algorithm allows HLA-DPB1 mismatches to be classified into permissive or non-permissive based on immunogenicity to a shared $\mathrm{T}$ cell epitope. It was observed that the non-permissive mismatches may further negatively affect the outcome of unrelated ASCT. ${ }^{1-2}$

Unrelated donor selection generally relies on matching for HLA-A, -B, -C, -DRB1 and -DQB1, but does not consider HLA-DP. In this study, we aimed to examine the impact of HLA-DPB1 compatibility on the outcome of matched unrelated ASCT. For this purpose, we studied 34 donor/recipient transplant pairs fully tested for the alleles HLA-A, B, C, DRB1, DQB1 and DPB1 in two different centers in Istanbul, Turkey.

\section{PATIENTS AND METHODS}

\section{Patients}

Thirty-four patients who received ASCT from an unrelated donor between January 2011 and January 2016 in adult bone marrow transplantation units of Istanbul Medipol University and Istanbul University, Istanbul Medical Faculty, were included in the analysis. All of the treatments before ASCT and the transplant decision were performed according to intention to treat basis on the relevant diagnoses for all patients. The expected prognosis were poor without an unrelated ASCT for all patients. The do- nor/recipient pairs were tested for HLA-A, -B, -C, - DR, -DQ alleles before the transplantation. ASCT was performed only for $9 / 10$ or 10/10 matching status. HLA-DP matching was performed retrospectively at the time of this study was designed.

\section{Methods}

In order to investigate the impact of HLA-DPB1 on the outcome of matched unrelated ASCT, patients' files were retrospectively examined. For this purpose, the data of age, gender, blood group and CMV serostatus of the patients and the donors, the diagnoses of the patients, the conditioning regimens used for stem cell transplantation, the stem cell source, number of stem cells infused, engraftment times, peripheral blood chimerism results, existence, grade and timing of graft-versus-host disease, existence of relapse and survival data were recorded. HLA matching status (matched vs. mismatched) and degree (permissive vs. nonpermissive) were examined between the donors and patients. Event-free-survival (EFS) was calculated as the time between the date of transplantation and the date that aGVHD occurrence or the date of the treatment related death or the the date of relapse or the last control date in patient's file (whichever occurs first). Overall-survival was calculated as the time between the date of transplantation and the time of death or the last control date in patient's file. All patients and their donor samples were tested for HLA-DPB1 in Istanbul University, Istanbul Medical Faculty, Department of Medical Biology. We typed HLA-DPB1 alleles in thirty-four patients who were unrelated donors and HLA typed by a sequencing-based method. DNA was extracted from peripheral blood using Invitrogen Library Builder. Amplifications were accomplished on a Perkin Elmer thermocycler. Sequencing was performed in both forward and reverse directions (Invitrogen SeCore ${ }^{\circledR}$ HLA Sequence-Based Typing Kit) DNA from sequencing reactions was electrophoresed on an ABI 3730XL DNA sequencer (Applied Biosystems, Foster City, CA, USA). Written informed consent was obtained from all individual participants according to the local ethics committee guidelines. 


\section{Statistical Analysis}

All statistical analyses were performed using SPSS (v.23.0) (SPSS Inc., Chicago, IL, USA) and STATA (v.14) (StataCorp LP,Texas,USA) software. Chisquare statistics were used to compare categorical variables among the different patient groups categorized according to the HLA-DPB 1 matching status. Analysis of continuous variables among the groups was performed using the Mann-Whitney $\mathrm{U}$ test. The influence of factors on engraftment, aGVHD, relapse, and survival was analyzed by using logistic regression models in multivariable analysis. Binary logistic regression analysis have been performed using the variables; diagnosis, conditioning regimen, HLA matching status, HLADPB1 compatibility (matched vs. mismatched) and degree of HLA-DPB1 mismatch (permissive vs.nonpermissive) for further determine the factors associated with aGVHD. Overall survival and event-free survival were analyzed using KaplanMeier methods and were compared using the logrank statistic. A p-value of less than 0.050 was considered to indicate statistical significance; all tests were 2-tailed.

\section{RESULTS}

\section{General Demographic Characteristics}

Out of 34 patients included in the study 21 (61.8\%) patients were male, 13 (38.2) patients were female. Median age was 32 (Range 20-60 yrs). 9 patients (26.5\%) diagnosed with ALL, 11 patients (32.4\%) diagnosed with AML, 4 patients diagnosed with CML (11.8\%), 3 patients $(8.8 \%)$ diagnosed with aplastic anemia, 4 patients $(11.8 \%)$ diagnosed with high-risk MDS and 3 patients (8.8\%) diagnosed with NHL underwent ASCT from a matched unrelated donor. Median donor age was 31 (Range: 1957). There was 17 male donor, 17 female donors. ABO blood groups were fully matched between recipient and donor in 11 transplants, however minor mismatch was observed in 12 transplants, major mismatch was observed in 8 transplants and bidirectional mismatch was observed in 3 transplantation procedure. CMV serostatus was positive in all recipients before the transplantation. 14 donors were positive, 20 donors were negative for $\mathrm{CMV}$ serology. During ASCT, TBI/Cy regimen was used in $2(5.9 \%)$ transplants, $\mathrm{Bu} / \mathrm{Cy}$ was used in 25 transplants $(73.5 \%)$, Flu/Bu regimen was used in 3 transplants (8.8\%) and $\mathrm{Flu} / \mathrm{Cy}$ regimen was used in 4 transplants $(11.8 \%)$. As the stem cell source, PMSCs were used in 31 transplants, bone marrow harvested stem cells were used in 3 transplants. Median stem cell dose infused was $6.05 \times 106 /$ kg (Range: 1.79-18.9x106). The combination of methotrexate, cyclosporine-A and ATG was used for GVHD prophylaxis in all patients. The disease status was complete remission in all recipients except for patients with aplastic anemia before ASCT. Main patient-, donor-, disease-, and transplantation characteristics and post-transplantation outcome are described in Table 1 and Table 2.

\section{Donor/recipient HLA Matching Status and Testing for HLA-DPB1}

HLA matching status was $9 / 10$ for 7 (20.6\%) recipient/donor pairs and 10/10 in 27 (79.4\%) recipient/ donor pairs before HLA-DPB1 testing. After HLADPB1 testing, it was noticed that, the compatibility of recipient/donor pairs was $9 / 12$ in $3(8.8 \%)$ transplants, $10 / 12$ in 19 (55.9\%) transplants, $11 / 12$ in $7(20.6 \%)$ transplants and $12 / 12$ in 5 (14.7) transplants. Within 27 transplants presumed to be transplated with a 10/10 HLA matching status before HLA-DPB1 testing, only 5 of them was fully matched for HLA-DPB1 after testing was performed. In the remaining 22 transplants, there was at least one antigen level mismatch (5 one antigen mismatch, 17 two antigen mismatch/full mismatch) according to HLA-DPB 1 testing. Likely 7 transplants presumed to be transplated with a $9 / 10$ HLA matching status before HLA-DPB1 testing, only 2 of them was fully matched for HLA-DPB1 after testing was performed. In the remaining 5 transplants, 2 of them were performed with one antigen mismatch and 3 of them were performed with fully mismatch in HLA-DPB1 testing. As a result, among the 34 transplant pairs, only 7 (20.6\%) were full-matched for HLA-DPB1, whereas there were one antigen mismatch in 7 (20.6\%) transplant pairs and 20 (58.8) transplant pairs were fully mismatched. Within 27 transplant pairs that have at least one antigen mismatch in HLA-DPB1, 
International Journal of Hematology and Oncology

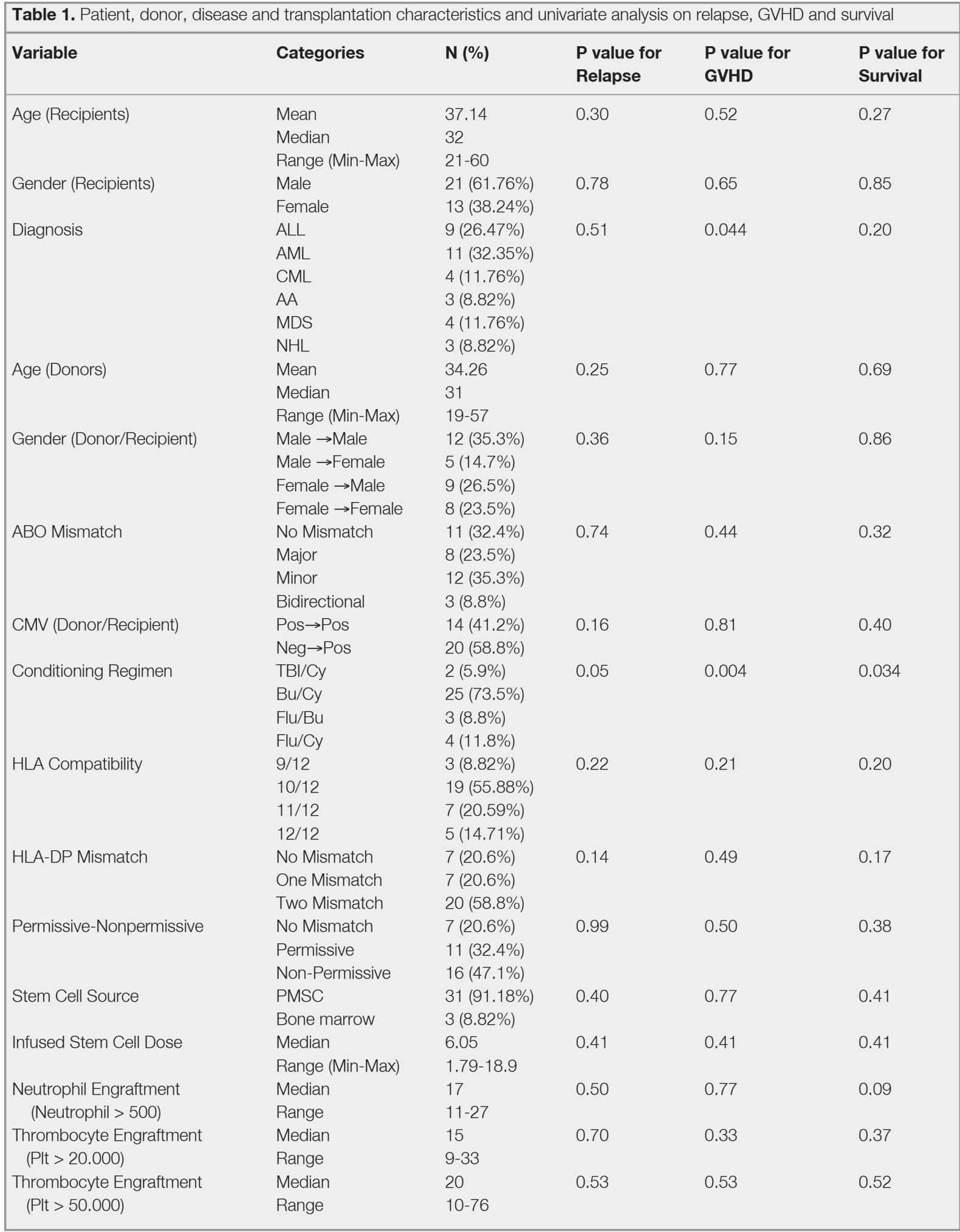

11 transplants was performed with permissive HLA-DPB1 mismatches and 16 transplants were performed with non-permissive HLA-DPB1 mismatches.

\section{Engraftment}

Neutrophil and thrombocyte engraftment were successfully occurred in the entire study group. Median time to neutrophil engraftment $\left(\geq 500 / \mathrm{mm}^{3}\right)$ was 


\begin{tabular}{|c|c|c|c|c|}
\hline Variable & Categories & N (\%) & $P$ value for relapse & $P$ value for Survival \\
\hline \multirow[t]{2}{*}{ GVHD General } & Absent & $9(26.47 \%)$ & 0.54 & 0.12 \\
\hline & Present & 25 (73.53\%) & & \\
\hline \multirow[t]{5}{*}{ Grade of GVHD } & No GVHD & $9(26.47 \%)$ & 0.66 & 0.28 \\
\hline & 1 & 2 (5.88\%) & & \\
\hline & 2 & 12 (35.29\%) & & \\
\hline & 3 & $8(23.53 \%)$ & & \\
\hline & 4 & 3 (8.82\%) & & \\
\hline \multirow[t]{2}{*}{ GVHD Skin } & Absent & 11 (32.35\%) & 0.95 & 0.17 \\
\hline & Present & $23(67.65 \%)$ & & \\
\hline \multirow[t]{2}{*}{ GVHD Gut } & Absent & 20 (58.82\%) & 0.62 & 0.20 \\
\hline & Present & $14(41.18 \%)$ & & \\
\hline \multirow[t]{2}{*}{ GVHD Liver } & Absent & $22(64.71 \%)$ & 0.40 & 0.61 \\
\hline & Present & 12 (35.29\%) & & \\
\hline \multirow[t]{2}{*}{ Relapse } & Observed & $6(17.6 \%)$ & NA & 0.53 \\
\hline & Not Observed & 28 (82.4\%) & & \\
\hline \multirow[t]{3}{*}{ Mortality } & $<100$ days & $5(14.7 \%)$ & NA & NA \\
\hline & $>100$ days & $10(29.4 \%)$ & & \\
\hline & Not Observed & $19(55.9 \%)$ & & \\
\hline
\end{tabular}

17 days (Range: 11-27 days), median thrombocyte engraftment was 15 days (Range:9-33 days) for platelets $\geq 20.000 / \mathrm{mm}^{3}$ and 20 days (Range: 10 76 days) for platelets $\geq 50.000 / \mathrm{mm}^{3}$. In univariate analysis, while the conditioning regimen $(\mathrm{p}=$ 0.021 ) was a significant factor for neutrophil engraftment time, HLA matching status $(\mathrm{p}=0.71)$ and non permissive HLA-DPB1 mismatch $(\mathrm{p}=0.46)$ found to be insignificant. Statistical analysis did not show any significant impact of HLA matching and HLA-DPB1 matching status on thrombocyte engraftment.

\section{Analysis of Factors Influencing aGVHD}

Among the entire study group, aGVHD was observed in $25(73.5 \%)$ patients, that was graded as I to IV. In univariate analysis diagnosis of the patient $(p=0.044)$ and intensity of conditioning regimen $(p=0.004)$ were significant factors for development of aGVHD.

aGVHD was observed in all of the 3 patients transplanted with 9/12 HLA matching status, 14 of the 19 patients transplanted with 10/12 HLA matching status, 6 of the 7 patients transplanted with $11 / 12$ HLA matching status and 2 of the 5 patients transplanted with 12/12 HLA matching status ( $\mathrm{p}=$ 0.212 ).

According to HLA-DPB1 matching status, aGVHD was observed in 4 of the 7 patients transplanted with a fully matched HLA-DPB1 donor, 5 of the 7 patients transplanted with one antigen mismatched donor and 16 of the 20 patients transplanted with two antigen mismatched (fully mismatched) donor. (p: 0.494) 7 of the 11 patients transplanted with permissive mismatches and 14 of the 16 patients transplanted with non-permissive mismatches experienced aGVHD $(\mathrm{p}=0.082)$.

In the entire patient population, 23 patients (67.6\%) experienced skin aGVHD ( Grade I: 4 patients, Grade II: 12 patients, Grade III: 5 patients, Grade IV: 2 patients), 14 patients experienced aGVHD of the gut (Grade I: 3 patients, Grade II: 7 patients, Grade III: 3 patients, Grade IV: 1 patient) and 12 patients experienced liver aGVHD ( Grade I 2 patients, Grade II: 6 patients, Grade III: 3 patients, Grade IV: 1 patient). HLA matching status (p: $0.357)$, HLA-DPB 1 compatibility $(\mathrm{p}=0.549)$ and non-permissive HLA-DPB1 mismatches was not significant factors for skin GVHD. However, for aGVHD of the gut, while the HLA matching status $(\mathrm{p}=0.627)$ and HLA-DPB1 mismatches $(\mathrm{p}=0.547)$ 
International Journal of Hematology and Oncology

\begin{tabular}{|llllll|}
\hline Table 3. Binary logistic regression analysis of factors affecting severe GVHD \\
\hline Variable & Coefficient $(\boldsymbol{\beta})$ & $\begin{array}{l}\text { Standart } \\
\text { error of } \beta\end{array}$ & OR & P Value & $\begin{array}{l}\text { \%95 Confidence } \\
\text { Interval }\end{array}$ \\
\hline Diagnosis & -0.054 & 0.328 & 0.947 & 0.868 & $0.498-1.801$ \\
Conditioning Regimen & -0.775 & 0.766 & 0.461 & 0.312 & $0.103-2.068$ \\
HLA Matching Status & 1.677 & 1.320 & 5.351 & 0.204 & $0.402-71.170$ \\
HLA-DPB1 Matching Status & 0.324 & 1.503 & 1.383 & 0.829 & $0.073-26.303$ \\
Degree of HLA-DPB1 Mismatch & 2.378 & 1.069 & 10.787 & 0.026 & $1.327-87.700$ \\
(Permissive/NonPermissive) & & & & & \\
\end{tabular}

were not significant, non-permissive mismatches were. (p: 0.006). Similarly, for the aGVHD of the liver, while HLA matching status $(\mathrm{p}=0.249)$ and HLA-DPB1 mismatches $(\mathrm{p}=0.423)$ were not significant, there was a medium level of significance of non-permissive mismatches $(\mathrm{p}=0.054)$.

When the occurrence of severe (Grade III-IV) aGVHD was taken into account, it has been observed that, 1 of 7 patients fully matched for HLA-DPB1 developed severe aGVHD, 1 of the 11 patients with permissive HLA-DPB1 mismatches developed severe aGVHD, however 9 of the 16 patients with nonpermissive HLA-DPB1 mismatches developed severe aGVHD $(p=0.019)$. This indicates that there may be significant correlation between the occurrence of severe aGVHD and nonpermissive mismatches.

Multivariate analysis with the variables; diagnosis, conditioning regimen, HLA matching status, HLA-DPB1 compatibility and degree of HLADPB1 mismatch (permissive vs.nonpermissive) have been performed showed that the degree of HLA-DPB1 mismatch was an independent factor for severe aGVHD (Table 3).

\section{Disease Relapse and HLA-DP1 Status}

Six patients (3 ALL, 1 AML, 1 high-risk MDS, 1 NHL patients) out of the 34 patients underwent a relapse. Among these 6 patients, 1 patient was fully matched for HLA-DPB1, 3 patients presented one antigen mismatch in HLA-DPB1 and 2 patients presented two antigen mismatch in HLA-DPB1. Statistical analysis did not show any significant impact of DPB1 mismatches on relapse. (p: 0.141)

\section{Analysis of Factors Influencing the Survival}

Estimated median event-free-survival (EFS) was 90 days (95\% CI: 0-246.3) for entire patient group. Estimated median EFS was 17 days $(95 \%$ CI : 13.7 - 20.2) for $9 / 12$ HLA matching status, 84 days (95\% CI: 0-229.6) for 10/12 HLA matching status, 90 days (95\% CI: 0-260.4) for 11/12 HLA Matching status and it was not reached for 12/12 HLA matching status. (p: 0.021) For HLA-DPB1 fully matched patients, estimated EFS was 372 days (95\% CI: 0-794.1). The estimated EFS was 90 days (95\% CI: 0-324.0) for one antigen mismatch in HLA-DPB1 and 52 days (95\% CI: 0-116.5) for two antigen mismatches in HLA-DPB1 $(\mathrm{p}=0.284)$. In HLA-DPB1 permissive mismatched transplants, estimated EFS was 225 days (95\% CI: 0-514.2), while it was 52 days (95\% CI: 0-113.5) in nonpermissive mismatched transplants $(\mathrm{p}=0.041)$ (Figure 1).

Fifteen (\%44.1) patients have died during the follow-up period. Transplant related mortality in first 100 days of ASCT was $14.7 \%$ (5 patients). 10 (29.4\%) patients have been deceased after first 100 days of ASCT. Of those 15 patients, 13 of them experienced aGVHD; the remaining 2 patients died of other causes, but not aGVHD ( $\mathrm{p}=0,035)$. All of the 3 patients transplanted with 9/12 HLA matching status, 8 of 19 patients transplanted with 10/12 HLA matching status, 2 of 7 patients transplanted with 11/12 HLA matching status, 2 of 5 patients transplanted with 12/12 HLA matching status have deceased $(\mathrm{p}=0.208)$. Three of 7 patients fully matched for HLA-DPB 1, 1 of 7 patients that have one antigen mismatch for HLA-DPB 1 and 11 of 20 patients that have two antigen mismatch for HLADPB1 died during the follow-up period ( $\mathrm{p}=0.174)$. Three of 11 patients with permissive HLA-DPB1 


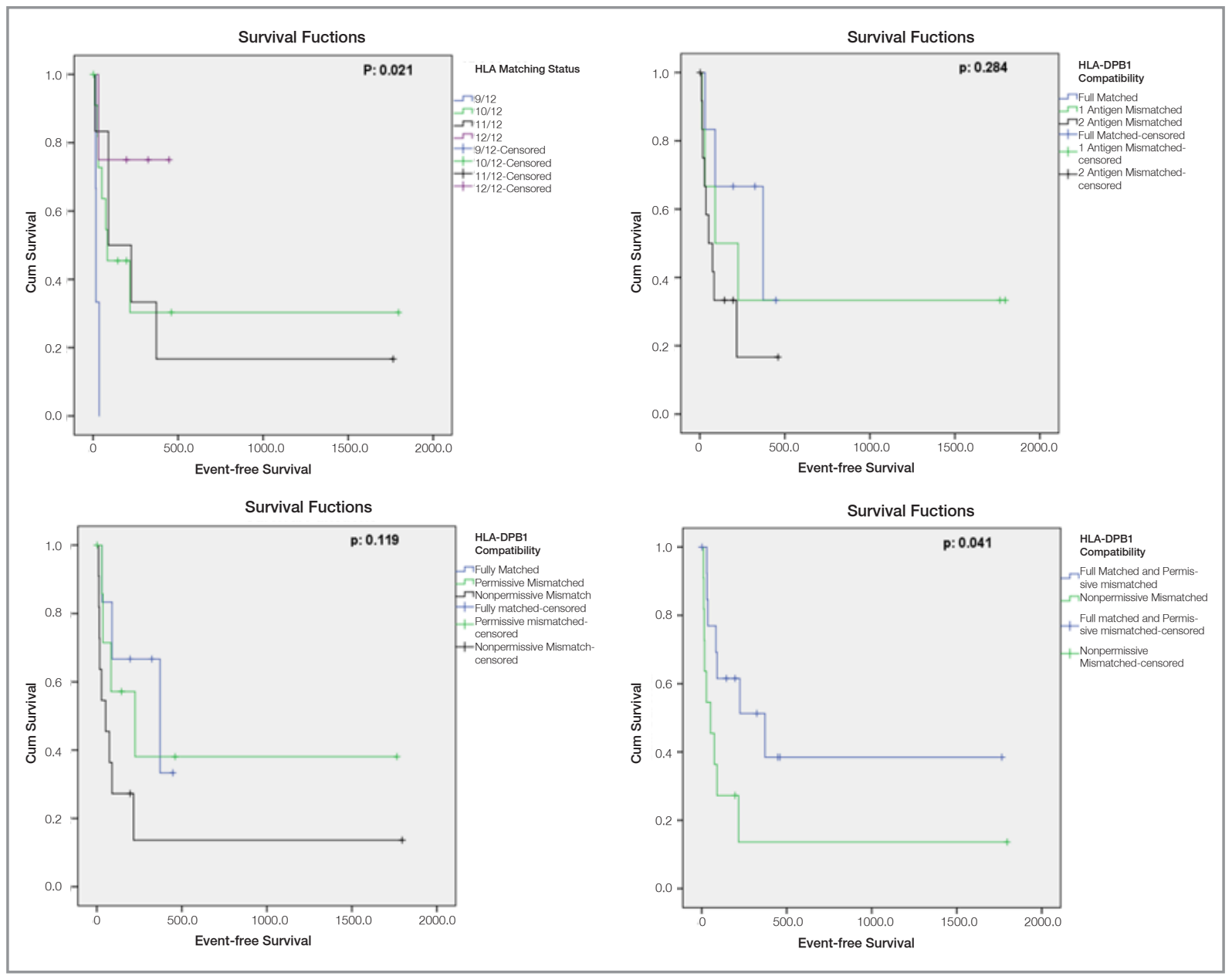

Figure 1. Event-free-survival curves according to HLA matching status and HLA-DPB1 compatibility

mismatches and 9 of 16 patients with nonpermissive HLA-DPB1 mismatches deceased in the follow-up ( $p=0.329$ ). 9/12 HLA matching status was a significant negative prognostic factor for survival when it is compared with 10-11-12/12 matching levels $(\mathrm{p}=0.041)$. Another interesting finding was, while none of 7 the patients transplanted with a reduced intensity conditioning died in the followup period, all 15 patients that have deceased in the follow-up were transplanted with a myeloablative conditioning regimen $(\mathrm{p}=0.017)$. However statistical analysis did not show any significant factor in multivariate analysis.

The mean overall survival (OS) was 1364 days in the entire patient group. The mean OS was 180 days (95\% CI: 3.6-356.4) for 9/12 matching status, 1010.3 days (95\% CI: 617.3-1403.3) for $10 / 12$ matching status, 1236.1 days $(95 \%$
CI: 305.3-637.6) for 11/12 matching status and 1939 days for $12 / 12$ matching status $(\mathrm{p}=0.236)$. The estimated mean OS was 1738.8 days $(95 \%$ CI: 854.8-2622.8) for HLA-DPB1 fully-matched transplants, 1476.8 days (95\% CI: 917.2-2036.3) for HLA-DPB1 one antigen mismatched transplants and 731.7 days (95\% CI: 424.0-1039.3) for two antigen mismatched transplants. $(\mathrm{p}=0.266)$ The estimated mean OS was 1275.5 days $(95 \%$ CI: 806.2-1744.8) for permissive HLA-DPB1 mismatched transplants, while it was 788.2 days $(95 \%$ CI: 369.7-1206.7) for nonpermissive HLA-DPB1 mismatched transplants $(\mathrm{p}=0.229)$ (Figure 2).

\section{DISCUSSION}

HLA-DP molecules are known to have many functions in human body. They can be effective in ei- 


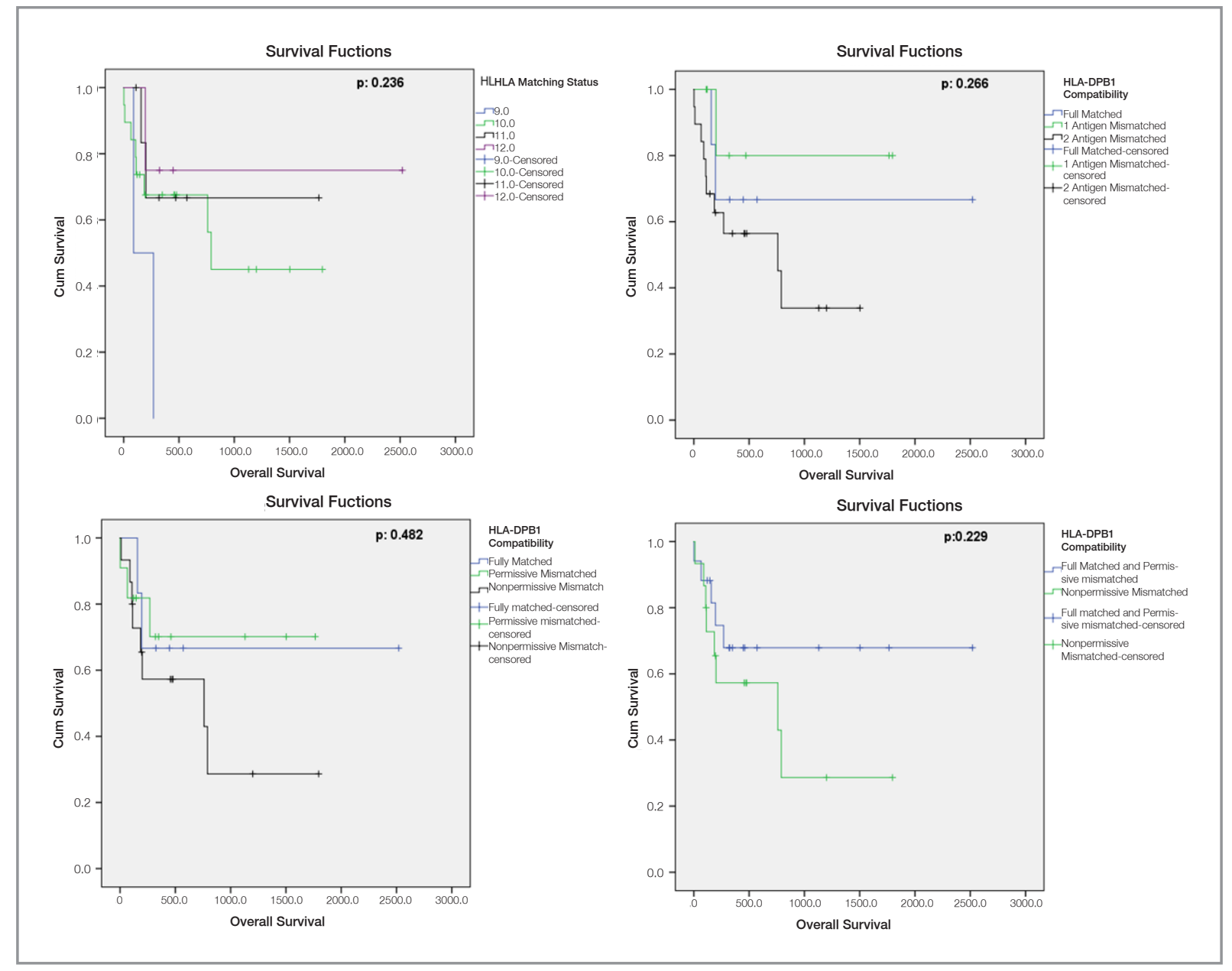

Figure 2. Overall survival curves according to HLA matching status and HLA-DPB1compatibility

ther inducing $\mathrm{T}$ cell responses or in antigen presentation to T cells. As of HLA-DP does play a role in immunogenicity, associations have been shown between certain DPB1 alleles and susceptibility to particular diseases. ${ }^{3-5}$ These observations shown that the HLA-DP molecule can act as a transplantation antigen. In transplant setting allogeneic HLADP-specific $\mathrm{T}$ cells have been identified in both GVHD and GVL cases.-9 However, the importance of this locus, as a transplantation antigen remained poorly understood. One of the reasons that this antigen has received less attention is the weak linkage disequilibrium, dependent on a recombination hot spot between the HLA-DQ and DP loci. As a result, HLA-DPB1 disparity is reported to be present in up to $5-10 \%$ of siblings and in $60-90 \%$ of unrelated donor transplants. In accordance with the literature, HLA-DPB1 disparity in at least one antigen level was $79.6 \%$ and only $20.6 \%$ of transplant pairs was fully identical for HLA-DPB1, in our study group. However HLA-DPB1 matching is not included in most donor selection procedures, despite growing evidence reporting a significant impact of disparity at this locus on post transplant complications.

On this subject, HLA-DP disparities and "T-cell epitope-based" HLA-DPB1 matching have became a research interest by several groups. ${ }^{10-27}$ For instance, in the study by Loiseau et al. reported increased frequency of severe aGVHD and poorer survival in two HLA-DP incompatibilities in a group of unrelated ASCT patients. ${ }^{10}$ In this study they were not able show a significant relationship between HLA-DP mismatches and disease relapse. Later, Shaw et al. studied the importance of HLA- 
DP matching in recipients of T-cell depleted unrelated ASCTs. ${ }^{11}$ In this study, a significant decrease in aGVHD and higher relapse rate was observed in fully matched HLA-DPB1 ASCTs. But there was no significant difference in engraftment times and OS. Gallardo et al. researched the importance of HLA-DPB1 mismatches in HLA-A-B-DRB1 identical sibling ASCTs. ${ }^{12}$ In their report, increased incidence of grade II-IV GVHD, have been observed in HLA-DPB1 mismatched transplantations. Interestingly, no significant difference was observed in terms of OS in this study. Thereafter, Zino et al, published their T-cell epitope based HLA-DPB1 matching results. ${ }^{13}$ In this study, the presence of nonpermissive HLA-DPB1 mismatches was correlated with an increased risk of grade II-IV aGVHD and transplantation-related mortality (TRM) but not relapse, as compared with the permissive group. There was also a marked but statistically unsignificant decrease in OS. Another article, that is published by Shaw et al, reported a higher relapse rate in HLA-DPB1-matched pairs as compared with HLA-DPB1-mismatched pairs in a group of 10/10 matched T-cell depleted unrelated ASCTs. ${ }^{14}$ In this study, researchers observed a higher rate of aGVHD, without a difference in TRM or OS in HLADPB1 mismatched transplantations. Fleischhauer et al reported an increased risk of graft failure with the presence of nonpermissive HLA-DPB1 mismatches, in a group of unrelated ASCT for betathalassemia patients. ${ }^{15}$ Interestingly there was not increased risk of GVHD and decreased OS in non permissive HLA-DPB1 disparities in this study population. Later, Shaw et al once again analyzed the clinical importance of HLA-DPB1 in unrelated ASCT. ${ }^{16-18}$ In this study HLA-DPB1 mismatch predicted an increased risk of aGVHD and the effect of HLA-DPB1 on relapse was significant only in patients matched for 10/10 alleles. There was an increased risk of mortality in the patients who were mismatched for HLA-DPB1, however this did not remain significant in multivariate analysis. In the study of Ludajic et al. HLA- DPB1 allele mismatches were found to be significantly associated with an increased incidence of grade II-IV aGVHD and worse overall survival. ${ }^{19}$ However HLA-DPB1 mismatches between recipients and donors had no influence on relapse in this study. In the study that Crocchiolo et al were published, there were signifi- cantly higher probabilities of GVHD, graft failure and poor OS in permissive compared with nonpermissive transplantations [20]. In the study of Kawase et al, they identified 6 HLA- DPB 1 mismatch combinations responsible for a decreased risk of relapse. ${ }^{21}$ Pairs with these combinations of HLADPB1 were associated with a significantly better overall survival than were completely matched pairs. Similarly, the study of Bettens et al also showed that HLA-DPB1 disparities have significant impact in terms of aGVHD and OS. ${ }^{22}$ Unlikely, in the study of Touzeau et al from France, HLADPB1 non permissive disparities did not cause any adverse prognosis in terms of GVHD, survival or relapse in a series of patients who underwent 10/10 HLA matched unrelated ASCT. ${ }^{23}$ In the study of Pidala et al, among 8/8 matched cases, HLA-DPB1 and -DQB1 mismatches resulted in increased aGVHD, and HLA- DPB1 mismatch had decreased relapse. ${ }^{24}$ In the study of Fleischhauer et al, nonpermissive mismatches associated with higher risks of TRM compared to permissive mismatches or allele matches. ${ }^{25}$ Another study from France, published by Gagne et al. could only show an adverse prognosis in two HLA-DPB1 mismatches for severe aGVHD. ${ }^{26}$ HLA-DPB1 disparities did not cause a worse outcome in terms of relapse and overall survival in this study. Similarly, the results of Pan et al showed that the presence of anti-HLA antibodies and their dynamic changes after transplantation were associated with increased occurrence of grades II to IV acute and chronic GVHD, higher treatment-related mortality, and reduced OS and disease-free survival. ${ }^{27}$ There was no significant difference in grades II-IV aGVHD, OS and disease free survival in patients receiving grafts from either HLA-DPB1 matched donors or HLA-DPB1 mismatched donors in this study. As we retrospectively examined our study group, we were not able to demonstrate the status of anti-HLA antibodies in our study group.

According to these data, the expected increase in the incidence of GVHD in HLA-DPB1 mismatched transplants was observed in only some of the studies, while in some studies was not. And, the expected decrease in relapse and survival rate with the increased rate of GVHD could be observed in only some of those studies. It is obvious that the 
results of these studies are not uniform and some of these studies confirm the impact of HLA-DPB1 disparities on transplantation outcome, while some of them do not. In addition, most of the data regarding this subject are obtained based on retrospective or registry studies, which the results are difficult to interpret. Therefore, our results from Turkey are important from our study. In our Turkish patient group, we did not observe any significant impact of HLA-DPB1 matching and T-cell epitope based HLA-DPB1 mismatches either on engraftment or graft failure. When the occurrence of severe (Grade III-IV) aGVHD was taken into account, we have observed that, nonpermissive HLA-DPB1 mismatches was a significant factor for development of severe aGVHD. Interestingly, there was a trend of increasing significance for the gut $(\mathrm{p}=0.006)$ and liver $(\mathrm{p}=0.054)$ GVHD but not for skin aGVHD in nonpermissive HLADPB1 mismatched transplantations which may be related with the negative impact of mismatched HLA-DPB1 in unrelated ASCT. In multivariate analysis, nonpermissive HLA-DPB1 mismatches also remained as an independent factor for severe aGVHD. Our results, did not show a significant impact of HLA-DPB1 mismatches on relapse. In survival analysis, both HLA-DPB1 disparities and non permissive mismatches showed a decreasing trend of event free and overall survival.

Nevertheless, we retrospectively examined the impact of HLA-DPB1 matching in 34 donor/recipient transplant pairs in this study. The nature of the retrospective study method and the count of our sample size are the major limitations of our study. However the reported results are from a very rare patient group in the field of stem cell transplantation. To our knowledge, our study is the first study that is reporting on this subject from Turkey. Additionally, our study also important because past reports never described the target organ of aGVHD in HLA-DPB1 mismatched transplantation.

In conclusion, our results indicate that DPB1 HLADPB1 mismatch is common in Turkish society and increases the level of HLA mismatch. HLA-DPB1 disparities increase the risk and severity of aGVHD in unrelated ASCT. HLA-DPB1 disparities, especially two antigen mismatches and non permissive mismatches have negative impact on survival after unrelated ASCT. Considering these results during donor selection may improve transplant outcomes in the setting of unrelated ASCT.

\section{REFERENCES}

1. Shaw BE, Arguello R, Garcia-Sepulveda CA, Madrigal JA. The impact of HLA genotyping on survival following unrelated donor haematopoietic stem cell transplantation. $\mathrm{Br} \mathrm{J}$ Haematol 150: 251-258, 2010.

2. Shaw BE, Robinson J, Fleischhauer K, et al. Translating the HLA-DPB1 T-cell epitope-matching algorithm into clinical practice. Bone Marrow Transplant 48: 1510-1512, 2013.

3. Yu M, Kinkel RP, Weinstock-Guttman B, et al. HLA-DP: a class II restriction molecule involved in epitope spreading during the development of multiple sclerosis. Hum Immunol 59: 15-24, 1998.

4. Bugawan TL, Angelini G, Larrick J, et al. A combination of a particular HLA-DP beta allele and an HLA-DQ heterodimer confers susceptibility to coeliac disease. Nature 339: 470-473, 1989.

5. Begovich AB, Bugawan TL, Nepom BS, et al. A specific HLADP beta allele is associated with pauciarticular juvenile rheumatoid arthritis but not adult rheumatoid arthritis. Proc Natl Acad Sci USA 86: 9489-9493, 1989.

6. Gaschet J, Gallot G, Ibisch C, et al. Acute graft-versus-host disease after bone marrow transplantation with a single $H\llcorner A$ DPB1*1001 mismatch: involvement of different TCRBV subsets. Bone Marrow Transplant 22: 385-392, 1998.

7. Ibisch C, Gallot G, Vivien R, et al. Recognition of leukemic blasts by HLA-DPB1-specific cytotoxic T cell clones: a perspective for adjuvant immunotherapy post-bone marrow transplantation. Bone Marrow Transplant 23: 1153-1159, 1999.

8. Rutten CE, van Luxemburg-Heijs SA, Griffioen M, et al. HLADP as specific target for cellular immunotherapy in HLA class II-expressing B-cell leukemia. Leukemia 22: 1387-1394, 2008.

9. Herr W, Eichinger $Y$, Beshay J, et al. HLA-DPB1 mismatch alleles represent powerful leukemia rejection antigens in CD4 T-cell immunotherapy after allogeneic stem-cell transplantation. Leukemia 31: 434-445, 2017.

10. Loiseau P, Espérou $H$, Busson $M$, et al. DPB1 disparities contribute to severe GVHD and reduced patient survival after unrelated donor bone marrow transplantation. Bone Marrow Transplant 30: 497-502, 2002.

11. Shaw BE, Potter MN, Mayor NP, et al. The degree of matching at HLA-DPB1 predicts for acute graft-versus-host disease and disease relapse following haematopoietic stem cell transplantation. Bone Marrow Transplant 31: 1001-1008, 2003. 
12. Gallardo D, Brunet S, Torres A, et al. Hla-DPB1 mismatch in HLA-A-B-DRB1 identical sibling donor stem cell transplantation and acute graft-versus-host disease. Transplantation 77: 1107-1110, 2004.

13. Zino E, Frumento G, Marktel S, et al. A T-cell epitope encoded by a subset of HLA-DPB1 alleles determines nonpermissive mismatches for hematologic stem cell transplantation. Blood 103: 1417-1424, 2004.

14. Shaw BE, Marsh SG, Mayor NP, et al. HLA-DPB1 matching status has significant implications for recipients of unrelated donor stem cell transplants. Blood 107: 1220-1226, 2006.

15. Fleischhauer K, Locatelli F, Zecca M, et al. Graft rejection after unrelated donor hematopoietic stem cell transplantation for thalassemia is associated with nonpermissive HLA-DPB1 disparity in host-versus-graft direction. Blood 107: 2984-2992, 2006.

16. Shaw BE, Gooley T, Madrigal JA, et al. Clinical importance of HLA-DPB1 in haematopoietic cell transplantation. Tissue Antigens 69 Suppl 1: 36-41, 2007.

17. Shaw BE, Gooley TA, Malkki M, et al. The importance of HLADPB1 in unrelated donor hematopoietic cell transplantation. Blood 110: 4560-4566, 2007.

18. Shaw BE. The clinical implications of HLA mismatches in unrelated donor haematopoietic cell transplantation. Int J Immunogenet 35: 367-374, 2008.

19. Ludajic K, Balavarca Y, Bickeböller H, et al. Impact of HLADPB1 allelic and single amino acid mismatches on HSCT. Br J Haematol 142: 436-443, 2008.

20. Crocchiolo R, Zino E, Vago L, et al ; Gruppo Italiano Trapianto di Midollo Osseo, Cellule Staminale Ematopoietiche (CSE) e Terapia Cellulare; Italian Bone Marrow Donor Registry. Nonpermissive HLA-DPB1 disparity is a significant independent risk factor for mortality after unrelated hematopoietic stem cell transplantation. Blood 114: 1437-1444, 2009.

21. Kawase T, Matsuo K, Kashiwase K, et al. Japan Marrow Donor Program. HLA mismatch combinations associated with decreased risk of relapse: implications for the molecular mechanism. Blood 113: 2851-2858, 2009.

22. Bettens F, Passweg J, Schanz U, et al. Impact of HLA-DPB1 haplotypes on outcome of 10/10 matched unrelated hematopoietic stem cell donor transplants depends on MHC-linked microsatellite polymorphisms. Biol Blood Marrow Transplant 18: 608-616, 2012.
23. Touzeau C, Gagne K, Sébille V, et al. Investigation of the impact of HLA-DPB1 matching status in 10/10 HLA matched unrelated hematopoietic stem cell transplantation: results of a French single center study. Hum Immunol 73: 711-714, 2012.

24. Pidala J, Lee SJ, Ahn KW, et al. Nonpermissive HLA-DPB1 mismatch increases mortality after myeloablative unrelated allogeneic hematopoietic cell transplantation. Blood 124: 25962606, 2014.

25. Fleischhauer $K$, Fernandez-Viña MA, Wang $T$, et al. Risk associations between HLA-DPB1 T-cell epitope matching and outcome of unrelated hematopoietic cell transplantation are independent of HLA-DPA1. Bone Marrow Transplant 49: 1176-1183, 2014.

26. Gagne K, Loiseau P, Dubois V, et al. Is there any impact of HLA-DPB1 disparity in 10/10 HLA-matched unrelated hematopoietic SCT? Results of a French multicentric retrospective study. Bone Marrow Transplant 50: 232-236, 2015.

27. Pan Z, Yuan X, Li Y, et al. Dynamic Detection of Anti-Human Leukocyte Antigen (HLA) Antibodies but not HLA-DP Loci Mismatches Can Predict Acute Graft-versus-Host Disease and Overall Survival in HLA 12/12-Matched Unrelated Donor Allogeneic Hematopoietic Stem Cell Transplantation for Hematological Malignancies. Biol Blood Marrow Transplant 22: 86-95, 2016.

\section{Correspondence:}

Dr. Bulent KANTARCIOGLU

Medipol Mega Hospital Complex

Hematology Klinigi

TEM Avrupa Otoyolu Goztepe Cikisi

No: 1, Bagcilar 34214

ISTANBUL / TURKEY

Tel: (+90-532) 5476208

e-mail: bulentkantarcioglu@gmail.com 